\title{
Mapping Wildfires Using Sentinel 2 MSI and Landsat 8 Imagery: Spatial Data Generation for Forestry
}

\author{
Sercan Gülci $^{1 *(D)}$, Kıvanç Yüksel ${ }^{1}$ (D), Selçuk GÜMÜŞ² ${ }^{(D)}$, Michael G. Wing ${ }^{3}$ (D) \\ ${ }^{1}$ Kahramanmaraş Sutcu Imam University, Department of Forest Engineering, 46040, Kahramanmaraş, Türkiye \\ ${ }^{2}$ Karadeniz Technical University, Department of Forest Engineering, 61080, Ortahisar/Trabzon, Türkiye \\ ${ }^{3}$ Oregon State University, Forest Engineering, Resources, and Management, Peavy Hall 338, Corvallis, OR 97331, USA
}

\begin{abstract}
Forests host diverse ecosystems that involve various habitats. There are many complex interactions between living and non-living things in most forests. It is important to conduct observations and assessments in large forestlands where short-term and long-term direct or indirect negative impacts may occur so that they are known and measured. Scientific studies have been carried out by utilizing the various data offered by today's advanced technology with satellite imagery becoming more readily available. In this study, differenced Normalized Burn Ratio ( $\mathrm{dNBR}=\Delta \mathrm{NBR})$ and satellite images with two different resolutions were used to generate pre- and post-wildfire spatial data. An area affected by wildfire in the Mediterranean Region of Turkey was selected as the study area. Google Earth Engine (GEE) and Geographic Information System (GIS) were used to delineate areas affected by wildfire using Sentinel-2 and Landsat 8 multispectral imagery. In order to compare the differences between the two sets of imagery, burn severity levels (low, medium-low, medium-high, and highest) and the effect of water surface were considered. For the most impacted burnt lands, areas detected with Sentinel 2 and Landsat 8 are $31.90 \%$ and $32.59 \%$, respectively. However, burn severity classes were also observed in water surface areas likely due to interactions between land cover and water reflectance. The overall results support the use of both satellite platforms and the dNBR for burn severity mapping in mediumand large-scale post-wildfire studies.
\end{abstract}

Keywords: Precision forestry, wildfire, remote sensing, post-fire, forest restoration, spatial data

\section{Introduction}

Innovative engineering knowledge and technology should be used to achieve sustainable management of forest resources, and to achieve the best use of economic, social and environmental aspects for present and future generations (FAO, 2021). The concept of sustainability aims to eliminate factors such as pollution, waste and poverty, while paying attention to the development of factors such as employment, productivity, wages, capital, savings, profits, knowledge and education (Barrow, 1993). In this case, it is necessary to use appropriate technology knowledge and systematic studies in the production of wood and wood-based products (such as timber production, wildfire prevention, carbon sequestration, drought, water quality, prevention of invasive species, pest control and economic benefits). Due to global climate change, various problems in forest ecosystems have become the focus of current research that addresses wildfires, droughts, and desertification that affect the natural structure of habitats (Çepel, 2003). As a result of improper land management and construction, many countries are struggling to address wildfires, droughts, invasive species, wildlife and insect damages (Stephens et al., 2018).

Wildfire can cause loss of life and property, and have a negative impact on the forest ecosystem. It also reduces the efficiency and diversity of forest ecosystem services. Wildfires and accompanying impacts that can span many years and have irreparable consequences on ecosystems (Nasi et al., 2002). Thus, interest in studies (active interventions in forests with mechanical methods) within the concept of sustainable forestry in the prevention and reduction of wildfire has increased. Forest operations is one potential tool to help manage forest resources while helping meet societal needs for sustainable forest management and wildfire mitigation.

Therefore, with the help of Geographic Information System (GIS) and Remote Sensing (RS) tools related to fire risk and severity in large forest areas, spatial models 
can be effectively used for forestry research (Küçük and Bilgili, 2006; Ateşoğlu, 2014; Akay and Şahin, 2019). In order to monitor and evaluate changes in large-scale forest ecosystems, a variety of remotely sensed data products are available that span multiple years (i.e., Landsat and Sentinel) (Gülci et al., 2019; Wulder et al., 2005). Today, the cloud computing environment eliminates the limitations of large-scale data processing and evaluation, providing a huge advantage in research with high processor capabilities (Nemani et al., 2011; Cavdaroglu, 2021; Konkathi and Shetty, 2021; Pan et al., 2021). Therefore, the use of RS and GIS technologies in many different scientific fields has been promoted and has rapidly increased with the development of technology.

RS tools can be effectively used for fire prevention projects, assessment and monitoring purposes, as well as detecting areas affected by wildfires, estimating fire severity and burn severity/ratio (Chuvieco, 2009; Fuller, 2000). RS (satellite or unmanned aerial vehicle-based imagery) related to wildfires can be divided into general groups including 1) fire intensity and severity, 2) determining the amount of potentially combustible materials, and 3) pre- and post-fire forest restoration (Wing et al., 2014). For example, Erten et al., (2004) performed a supervised classification method with Landsat TM satellite imagery to identify burnt areas and vegetative regrowth. Gülci et al., (2016) conducted an assessment of forest conditions after timber harvesting by using thermal imagery. Aricak et al. (2012) determined potential combustible material characteristics in forestlands (tree species, mixture, crown closure, and age stages) within the scope of using high-resolution satellite imagery to identify fire-sensitive areas. Çoban and Özdamar (2014) investigated the relationship between wildfires, and topography and land cover dynamics using the Normalized Vegetation Difference Index (NDVI) and NBR index (Çoban and Özdamar, 2014). Atun et al. (2020) used the Normalized Burning Ratio (NBR), the differenced Normalized Burning Ratio (dNBR) and Relative Burning Ratio (RBR) index to determine the risk level of wildfires and fire-disturbed forests through the use of Sentinel 2 multispectral bands. Sabuncu and Özener (2019) explored an index correlation between NBR, NDVI, dNBR and the differenced Normalized Vegetation Difference Index (dNDVI) derived from Landsat spectral bands to determine the areas damaged by wildfire (Sabuncu and Özener, 2019). In addition, Gülci (2021) applied the dNBR index to study the effect of burning severity on the unit price of timber in stumpage sales.

In this study, pre-fire and post-fire mapping and burn severity/ratio estimation were carried out using band ratio, which is one of the traditional methods. The results of obtained dNBR estimations by using Sentinel 2 MSI and Landsat 8 were compared and discussed statistically. The response of dNBR to water-covered surfaces was also evaluated based on the sensitivity of fire detection.

\section{Materials and methods}

\subsection{Materials}

\subsubsection{Study area}

The study area is located at $35^{\circ} 25^{\prime} 10^{\prime \prime}-37^{\circ} 18^{\prime} 15^{\prime \prime}$ east longitudes and $35^{\circ} 34^{\prime} 35^{\prime \prime}-37^{\circ} 22^{\prime} 10^{\prime \prime}$ north latitude within the border of Karaisalı and İmamoglu districts of Adana Province in the eastern Mediterranean region. Turkish red pine and maquis are widely distributed as typical species reflecting the Mediterranean region. The average elevation of the land in the study area ranges from 200-250 m, with a river located within the fire area (Figure 1).

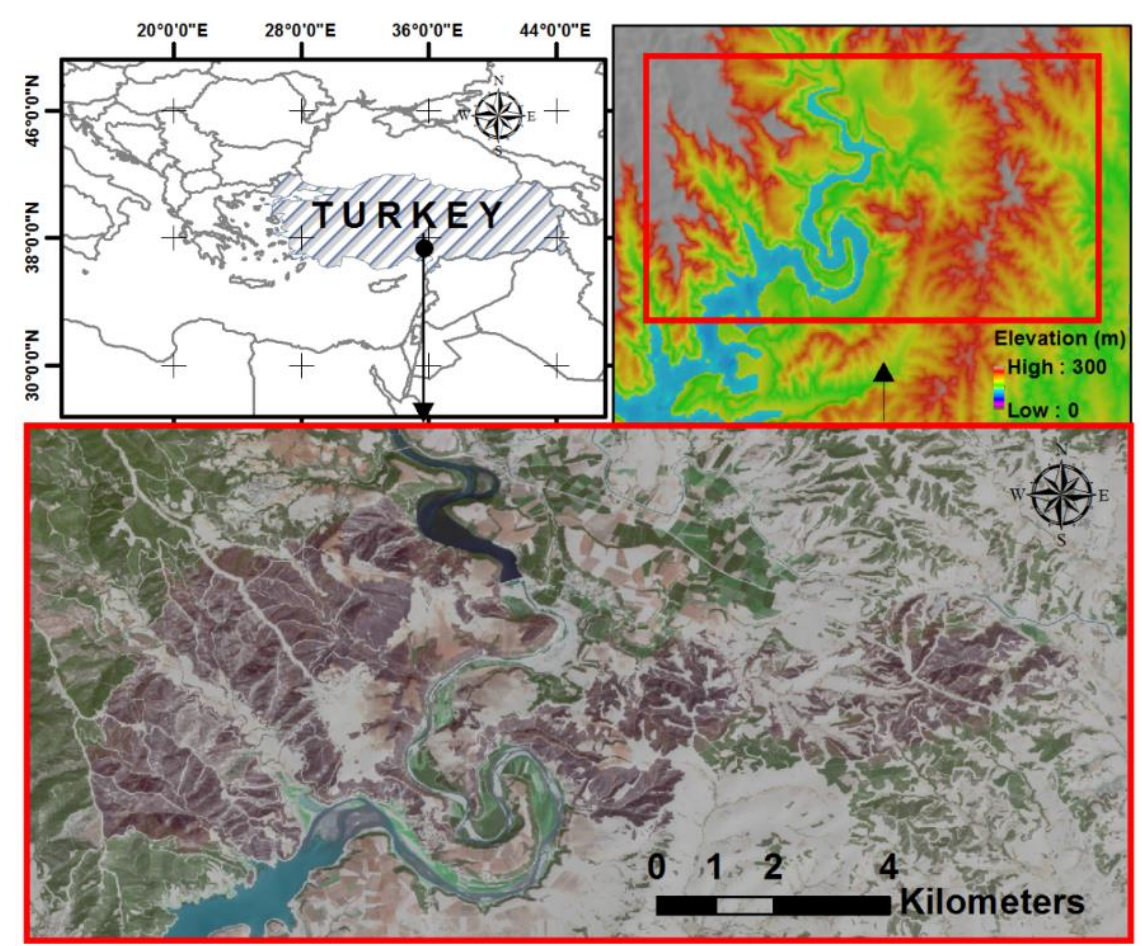

Figure 1. Geographical location of the study area, post-fire view on satellite image and elevation map 


\subsubsection{Satellite Images and Features}

The satellite images of the study area that were acquired were Sentinel-2 (S2) Multispectral Instrument (MSI) and the Landsat 8 (L8). These satellites provided multispectral images with different temporal and spatial resolutions, and are useful for examining burn severity.

S2 consists of two satellites named S2A and S2B. S2A was launched in 2015 and S2B was launched in 2017. They orbit at an angle of 180 degrees to each other, and their orbits are inclined at 98.5 degrees. The mission of S2 is to observe climate change, land monitoring, emergency management and security. It is equipped with high-resolution multispectral bands with resolutions of $10 \mathrm{~m}, 20 \mathrm{~m}$ and $30 \mathrm{~m}$ (Table 1) (ESA, 2021).
The L8 with Operational Land Imager (OLI) and Thermal Infrared Sensor (TIRS) sensors was launched on February 11, 2013. Sensor wavelengths include blue band $(0.433-0.453 \mu \mathrm{m})$ and short-wave infrared band $(1,360-1,390 \mu \mathrm{m})$. It has strong water vapor absorption capacity and can be used for ocean observation in coastal areas. The band characteristics, center wavelength and resolution of L8 are given in Table 2 (USGS, 2021).

A variety of images were acquired from the satellites representing a temporal range of pre- and post-fire (Table 3 ). The imagery such that cloud cover was minimized were selected.

Table 1. Features of Sentinel-2 MSI instruments

\begin{tabular}{lcc}
\hline Sentinel-2 Bands & Central wavelengths $(\mu \mathrm{m})$ & Resolution $(\mathrm{m})$ \\
\hline 1-Coastal aerosol & 0.443 & 60 \\
2-Blue & 0.490 & 10 \\
3-Green & 0.560 & 10 \\
4-Red & 0.665 & 10 \\
5-Red edge-1 & 0.705 & 20 \\
6- Red edge-2 & 0.740 & 20 \\
7- Red edge-3 & 0.783 & 20 \\
8-Near infrared (NIR) & 0.842 & 10 \\
8A-Near infrared narrow & 0.865 & 20 \\
9-Water vapor & 0.945 & 60 \\
10-Shortwave infrared/Cirrus & 1.375 & 60 \\
11- Shortwave infrared-1 (SWIR1) & 1.610 & 20 \\
12- Shortwave infrared-2 (SWIR2) & 2.190 & 20 \\
\hline
\end{tabular}

Table 2. Features of Landsat 8 instruments

\begin{tabular}{lcc}
\hline Landsat 8 Bands & Wavelengths $(\mu \mathrm{m})$ & Resolution $(\mathrm{m})$ \\
\hline 1-Coastal / Aerosol & $0.433-0.453$ & 30 \\
2-Blue & $0.450-0.515$ & 30 \\
3-Green & $0.525-0.600$ & 30 \\
4-Red & $0.630-0.680$ & 30 \\
5- Near infrared (NIR) & $0.845-0.885$ & 30 \\
6- Short wave infrared-1 (SWIR1) & $1.560-1.660$ & 30 \\
7- Short wave infrared-2 (SWIR2) & $2.100-2.300$ & 30 \\
8-Panchromatic & $0.500-0.680$ & 15 \\
9-Cirrus & $1.360-1.390$ & 30 \\
10-Termal infrared (TIRS1) & $10.30-11.30$ & 100 \\
11-Termal infrared TIRS2) & $11.50-12.50$ & 100 \\
\hline
\end{tabular}


Table 3. General information about the images used in this study

\begin{tabular}{lccc}
\hline \multirow{2}{*}{ Sensor IDs } & \multirow{2}{*}{$\begin{array}{c}\text { Image } \\
\text { count }\end{array}$} & \multicolumn{2}{c}{ Pate interval } \\
\cline { 3 - 4 } & 4 & July $01^{\text {th }}-17^{\text {th }}, 2021$ & August $02^{\text {nd }}-18^{\text {th }}, 2021$ \\
\hline LANDSAT/LC08/C01/T1_SR & 17 & July $02^{\text {nd }}-24^{\text {th }}, 2021$ & August $01^{\text {th }}-18^{\text {th }}, 2021$ \\
COPERNICUS/S2 & & &
\end{tabular}

\subsection{Methods}

\subsubsection{The Production of the Fire Severity Maps}

The detailed information given on the UN-SPIDER (United Nations Platform for Space-based Information for Disaster Management and Emergency Response) online platform was followed (UNOOSA, 2018). Burn severity maps were created by processing multispectral band satellite images in Google Earth Engine (GEE)
(Figure 2) (Gorelick et al., 2017). Then, the maps obtained in the cloud environment were transferred to a computer workstation for further evaluation. A series of GIS operations such as classification, overlay, clipping, calculation and visualization were carried out using ERDAS (Erdas, 1997) and ArcGIS 10 software (Esri, 2013).

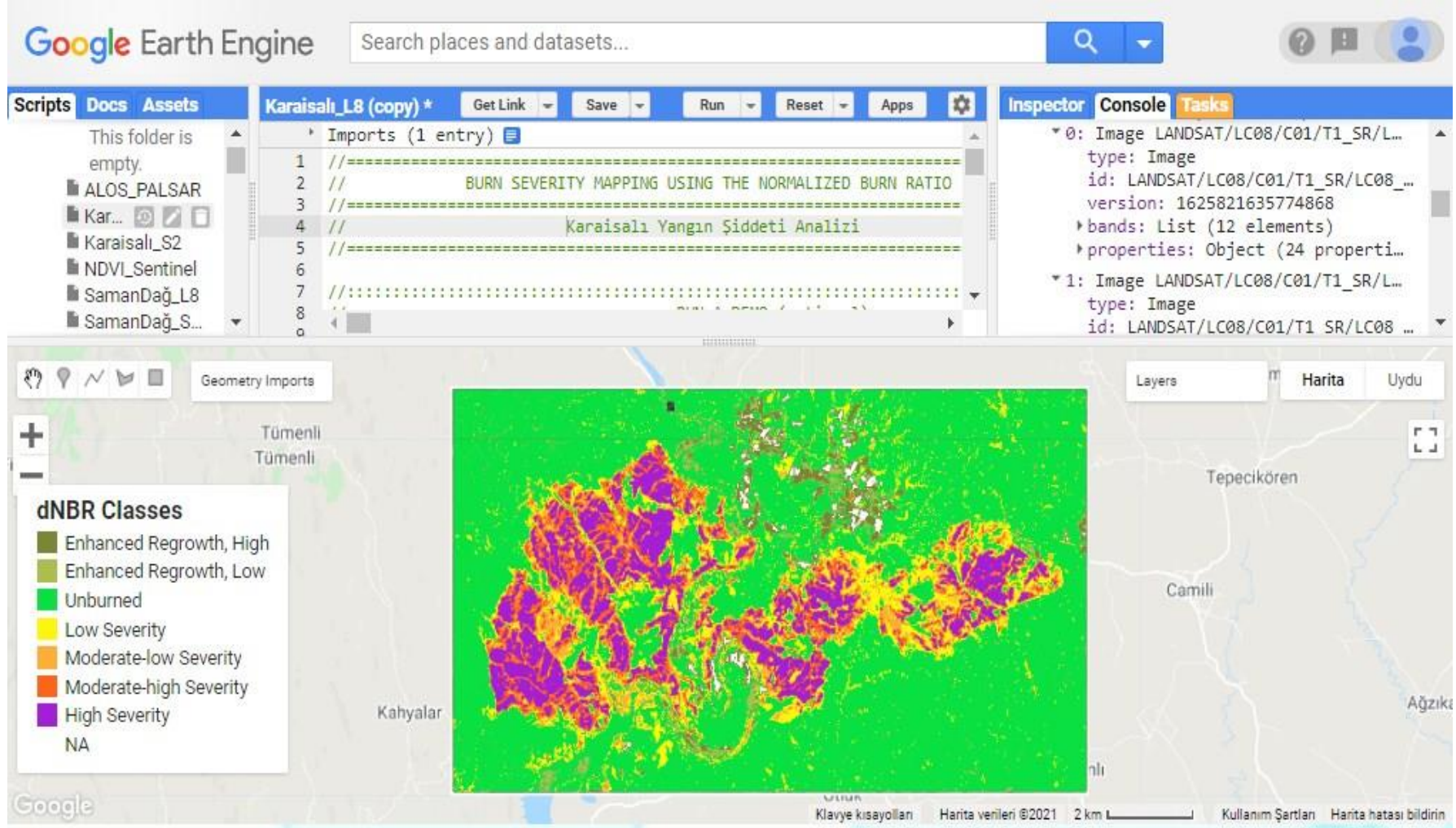

Figure 2. Screenshot of the online interface of the GEE code editor

Prediction maps of burn severity were created using S2 and L8 multispectral bands. The differenced normalized burn ratio (dNBR) technique was used to create burn severity maps. dNBR (Equation 1) is obtained by taking the difference of the NBR (Equation 2) index pre- and post-fire (Key and Benson, 2006; Miller and Thode, 2007; Keeley, 2009). Band 8 (NIR) and Band 12 (SWIR) were used for S2-based fire maps (Equation 1). Band 5 (NIR) and Band 7 (SWIR-2) were used for L8-based fire maps (Equation 2).

$N B R=\frac{N I R-S W I R}{N I R+S W I R}$ $d N B R=N B R_{\text {Pre-fire }}-N B R_{\text {Post-fire }}$

\subsubsection{Definition of Burn Severity Classes}

The unitless numbers obtained from dNBR are divided into 7 categories in order to correctly separate the burned area from the unburned area (Table 4). The classes recommended by USGS-FIREMON (United States Geological Survey-Fire Impact Monitoring and Inventory Protocol) were considered in the classification of burn severity (USDA, 2006). The first three categories were assumed to be areas that were not affected by fire, unburned or unexposed to fire. 
Table 4. Burn severity levels obtained calculating dNBR (USDA, 2006)

\begin{tabular}{clc}
\hline Classes & Severity levels & dNBR value \\
\hline 1 & Enhanced regrowth, high (post-fire) & $<-0.25$ \\
2 & Enhanced regrowth, low (post-fire) & -0.25 to -0.10 \\
3 & Unburned & -0.10 to 0.10 \\
4 & Low severity & 0.10 to 0.27 \\
5 & Modorate- low severity & 0.27 to 0.44 \\
6 & Moderate- high severity & 0.44 to 0.66 \\
7 & High severity & $>0.66$ \\
\hline
\end{tabular}

\subsubsection{Accuracy Assessment}

The accuracy analysis of the classified maps was carried out on the reference image produced by the combination of spectral bands in the visible range. The accuracy analysis was performed to understand the success of unburned and burned area classification, not the estimated accuracy of the burn severity value. Classification accuracy was demonstrated by assigning a total of 120 randomly selected control points to the two classes in the study area and were divided equally.

A confusion matrix table was used in the accuracy analysis to consider user error, producer error, and Kappa value (Congalton, 2001). Then, visual controls were made by superimposing the merged images of the land cover in the visible range (RGB) on the estimated map (Figure 3).
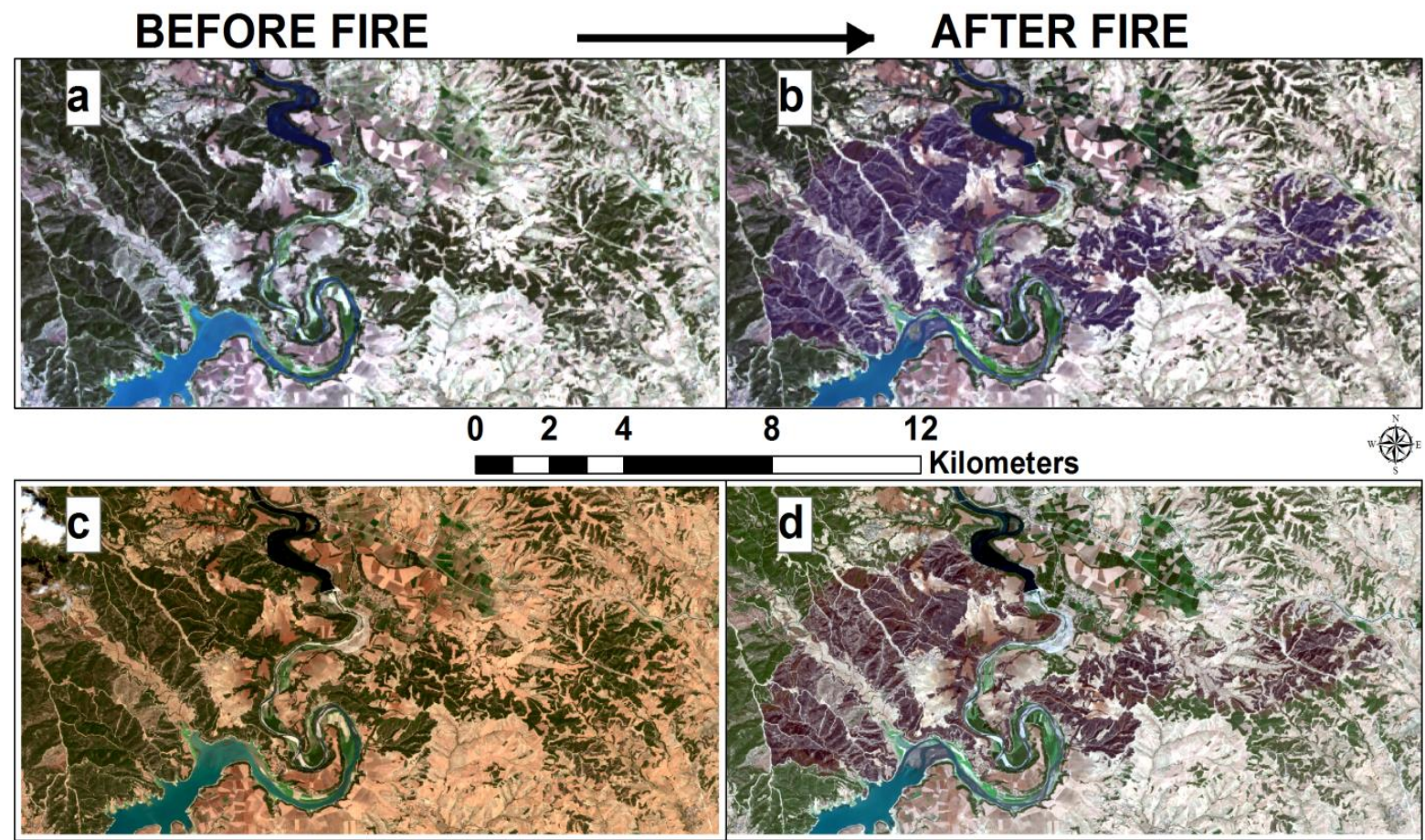

Figure 3. L8 (a-b) and S2 (c-d) pre- and post-wildfire images

\section{Results and discussion}

\subsection{Maps of Wildfire and Severity Classes}

Considering the limited size of the study area, GEE was able to complete the creation of the fire severity maps within a few minutes. Spectral band images with desired properties were easily exported from the cloud environment. Therefore, GEE has an advantage in terms of processor and data storage costs in comparison to noncloud based computing options. With the help of the code editor, the prediction map was generated by selecting the L8 and S2 multispectral bands with the least cloudiness. For S2 and L8, the total area of the study object is calculated to be 16569.15 and 16586.73 hectares, respectively (Figure 3). Data losses occurred as a result of images having different resolutions and image processing. Therefore, the total area difference of the study boundary as captured by the two satellites was calculated to be approximately $0.1 \%$. In addition, the water surface area in the S2 and L8 images was calculated to be approximately 1300 hectares. Although no fire was observed, the detection sensitivity of burning severity by L8 was lower than the S2. In Sentinel 2, the cloudy area was estimated as the area with high vegetation growth class in the dNBR-based burn severity map. In the study area, in forest areas with no road network or low road density, the severity of burning was estimated to be higher (Figure 4). 


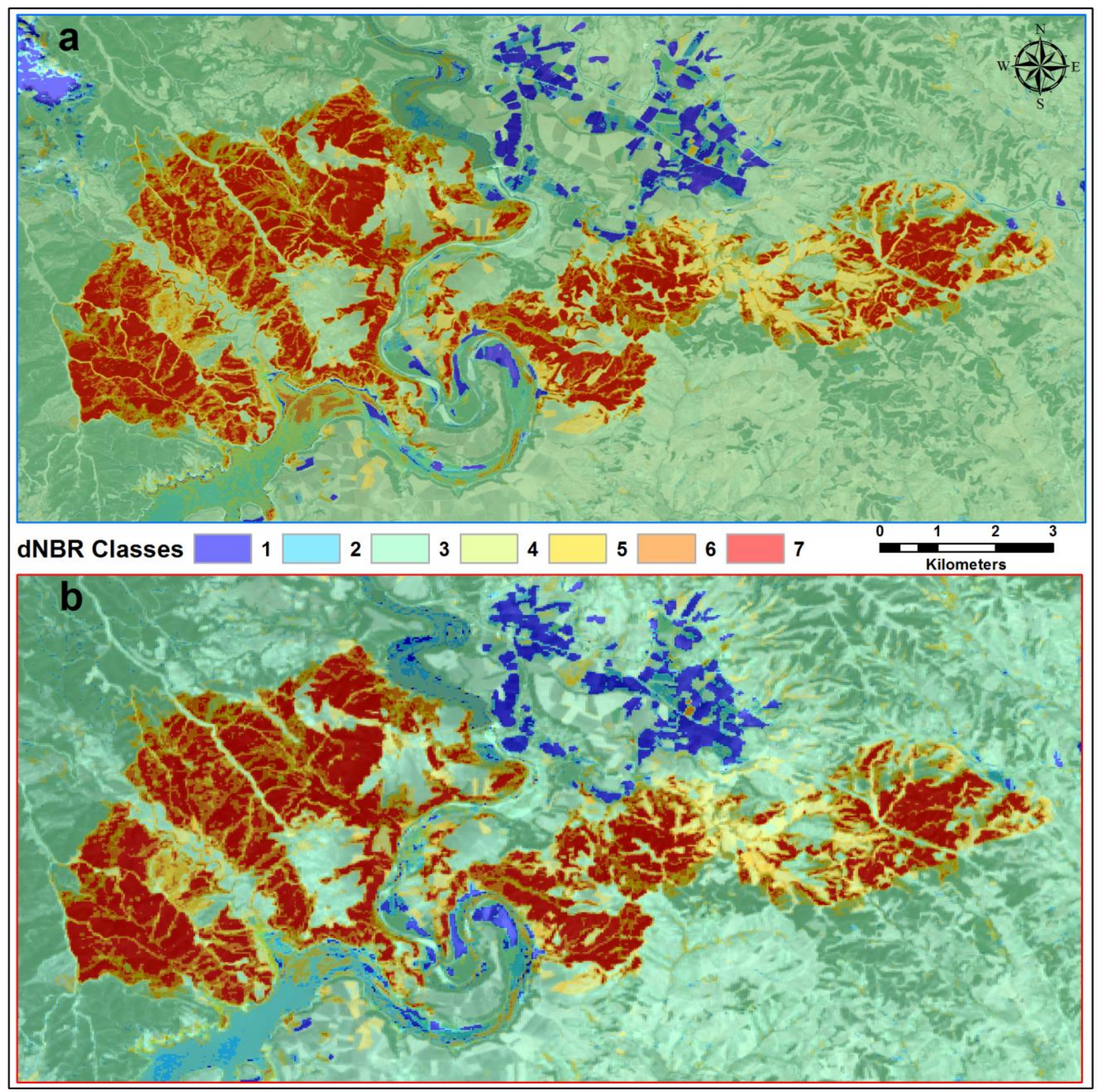

Figure 4. The dNBR burn severity maps of S2 (a) and L8 (b)

Thanks to the high resolution images of the S2, more spatial detail is available and consequently, the S2 imagery can produce better quality visual maps than the L8 imagery. The S2 imagery can also be an effective factor in correctly estimating the highest burn severity class from other burn classes (Quintano et al., 2018). The areal performance difference between the S2 $(\downarrow)$ and L8 $(\uparrow)$ images is $69 \%$ in the detection of the estimated area of the high burn severity class. In the L8 satellite image, it is estimated that the total size of the burnt area increased by 505.5 hectares. When evaluating the entire study area, the average of the absolute difference between the percentage of burned and unburned areas is approximately $1.23 \%$.

Considering only the classes within the boundaries of the area exposed to the fire (Figure 1;3), the average of the absolute differences in the percent of the areal distribution of burn severity was calculated at about $2 \%$ (Table 5) in the dNBR-based burning severity classes (Figure 4). Areas with different burn severity classes (low (4), medium-low (5), moderate- high (6) and high burn severity (7)) were estimated to account for about $28 \%$ of the total area. There was a partial decrease in the burn severity class areas after subtracting water surface area from the total area.

Different variables (such as stand parameters and topography) that are effective in increasing or reducing the severity of burning within the forestry range can be used as parameters in GIS analysis. However, it is necessary to investigate the dNBR results of different forest types (such as canopy stratification and stand structure) to determine the estimated success rate of burn severity for different forest stands (Cocke et al., 2005; Çoban and Özdamar, 2014). In addition, it should be taken into account that there is no universally accepted classification when using satellite imagery to determine the burn severity in places where wildfires occur. For example, Gülci (2021), who examined post-fire harvesting and stumpage sales, did not find a high relationship between the severity of the fire and the price demand of forest contractors in the forest stands. 
Table 5. The ratio of unburned and burn severity estimated using the multispectral bands of the S2 and L8 satellites

\begin{tabular}{|c|c|c|c|c|c|c|}
\hline \multirow[b]{2}{*}{ Classes } & \multicolumn{3}{|c|}{$\mathrm{S} 2$} & \multicolumn{2}{|c|}{ L8 } & \multirow[b]{2}{*}{ Differences } \\
\hline & $\begin{array}{l}\text { Area (with water } \\
\text { surface) } \%\end{array}$ & $\begin{array}{c}\text { Area (excluded } \\
\text { water surface) } \%\end{array}$ & Differences & $\begin{array}{c}\text { Area (with water } \\
\text { surface) } \%\end{array}$ & $\begin{array}{c}\text { Area (excluded } \\
\text { water surface) } \%\end{array}$ & \\
\hline Unburned & 72.29 & 72.92 & - & 69.63 & 69.65 & - \\
\hline 4 & 7.92 & 6.96 & + & 9.36 & 8.85 & + \\
\hline 5 & 4.83 & 4.65 & + & 5.27 & 5.02 & + \\
\hline 6 & 6.80 & 6.83 & - & 6.39 & 6.58 & - \\
\hline 7 & 8.16 & 8.64 & - & 9.35 & 9.90 & - \\
\hline Total & 100 & 100 & & 100 & 100 & \\
\hline
\end{tabular}

\subsection{The Effect of Water Surface Area}

According to the results of dNBR, there is evidence of burn impacts in areas that are coincident with water surfaces. This includes 4-5-6 and 7-class burn areas including the range from low to high burn severity. Between $30.5 \%$ and $35.1 \%$ of the area burned for L8 and S2 are located on the water surface area and edge, respectively (Figure 5). This showed that in the use of the dNBR index, according to the L8 and S2 imagery, there may be detections in the fire damaged area classes in the

areas covered with water (Bolton et al., 2015). Hence, in this and similar studies, attention should be paid to the effect of different land cover types on wildfire mapping. The amount of energy from the sun can cause significant differences in reflectance values, depending on the chemical composition and physical properties of the land cover and surface (Picotte et al., 2021). This will have an impact on the results obtained from the satellite images considering the wavelength sensitivity of instruments.
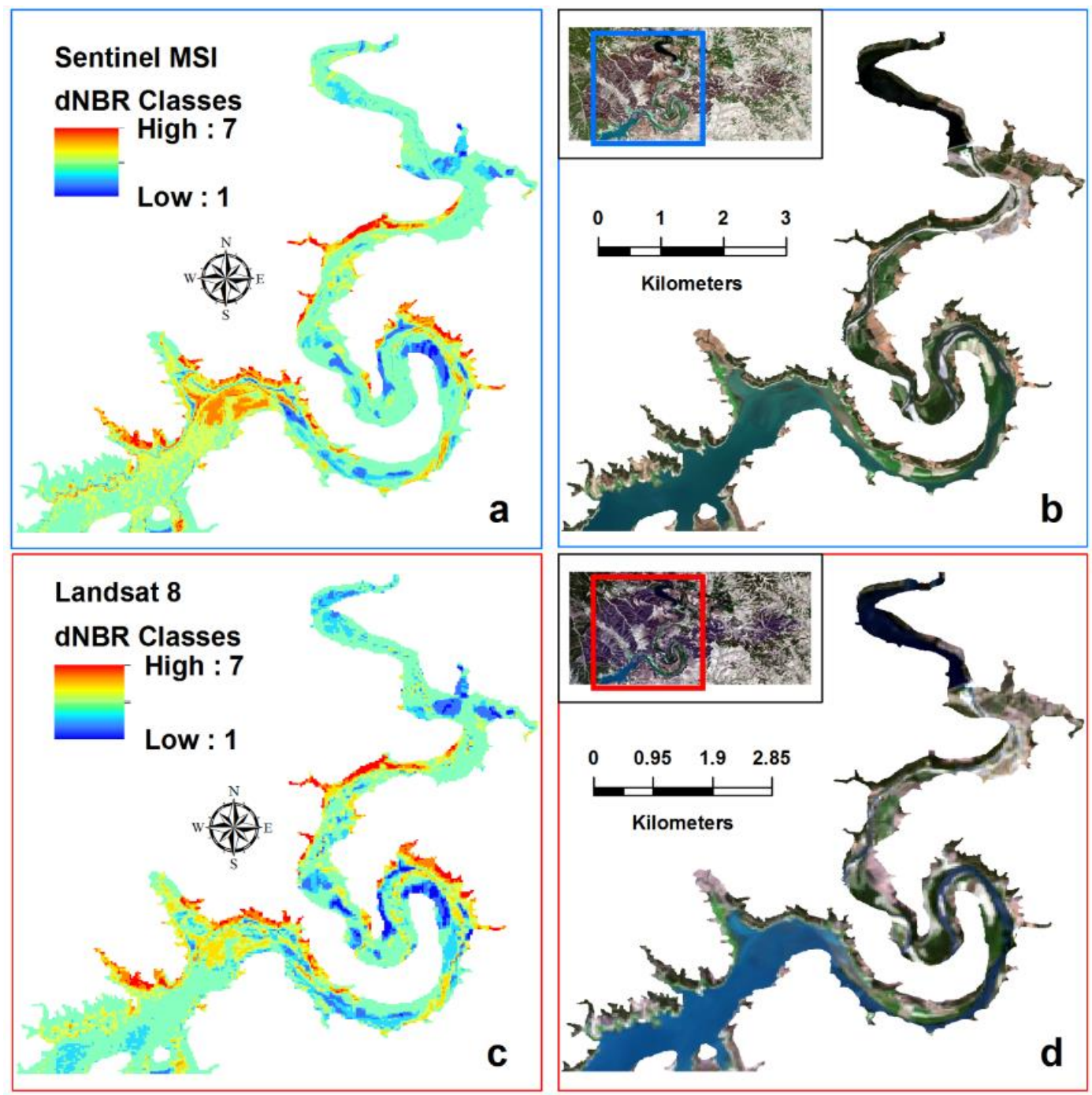

Figure 5. The classes of the burn severity estimated in the water surface area. The spatial distribution of the dNBR classes generated by the S2 MSI (a), and the location in the S2 RGB image (b). The spatial distribution of the dNBR classes generated by L8 (c), and the location in the L8 RGB image (d). 


\subsection{Accuracy Analysis}

The burn severity maps generated by the two satellite images were divided into two types: burning zone and non-burning zone. Through this classification, the fire area prediction accuracy of L8 and S2 dNBR maps were $91.67 \%$ and $93.33 \%$, respectively. Taking into account the Kappa statistics, the classification success rate obtained from these two data sources is very high. In this study, the evaluation was conducted in two different classes. If the number of classes increases, the kappa value may change (Congalton, 2001). Both satellite images, which have a slight difference between them, have the potential for the production of wildfire maps (Table 6).

Table 6. The results of the overall accuracy for L8 and S2 classification

\begin{tabular}{lccccccc}
\hline Sensor & Classes & Reference & Classified & Correct & $\begin{array}{c}\text { Producers } \\
\text { Accuracy }\end{array}$ & $\begin{array}{c}\text { Users } \\
\text { Accuracy }\end{array}$ & $\begin{array}{c}\text { Kappa } \\
\text { Value }\end{array}$ \\
\hline \multirow{2}{*}{ L8 } & Unburned & 66 & 60 & 58 & 87.88 & 96.67 & \\
& Burned & 54 & 60 & 52 & 96.30 & 86.67 & \\
& Total & 120 & 120 & 110 & & & 0.8333 \\
\hline \multirow{2}{*}{ S2 } & Unburned & 68 & 60 & 60 & 88.24 & 100 & \\
& Burned & 52 & 60 & 52 & 100 & 86.67 & \\
& Total & 120 & 120 & 112 & & & 0.8667 \\
\hline
\end{tabular}

\section{Conclusions}

In this study, dNBR technology was used to detect and map burned forest areas with high accuracy. However, there was a wrong estimate of the land surface covered by water. Land cover should be considered in the dNBR study to be applied to similar areas. As a result of processing S2 and L8 satellite images, similar spatial results were obtained.

Archived satellite images such as Landsat 8 and Sentinel2 MSI have immense potential to be used in the determination and evaluation of forest area disturbance. Researchers and decision makers can consider the severity of wildfire in pre- and post-fire recovery or harvesting plans within the scope of forestry research. Image classification results can be used as spatial data in decision support systems as a quick means to detect and map fire areas. On the other hand, the effects of land cover types and stand parameters on the prediction performance of dNBR and burn severity should be studied.

Forestry studies that require long-term planning, monitoring and evaluation, are very difficult without technology. Forests are natural habitats, which are affected by changes in climatic conditions and human activities. Therefore, technology is valuable in observing the forest and understanding the different relationships between forest and fire. Remote sensing technology can play an important role in the planning of the post-fire process, especially in the fight against wildfires. There are many developments that could be studied in the application of the dNBR method, but it was successfully applied in the detection of the fire zone in this study areas.

\section{Acknowledgements}

Google Earth Engine (GEE) and Google Inc providers were used in the analysis. We thank the U.S. Geological Survey (USGS) and European Space Agency (ESA) for providing free access to Copernicus Sentinel MSI and Landsat images for scientific research.

\section{Ethics Committee Approval: N/A.}

Peer-review: Externally peer-reviewed.

Author Contributions: Concept: S.G and K.Y; Design: S.G and K.Y.; Supervision: S.G., K.Y., S.G. and M.G.W; Resources: S.G and K.Y.; Data Collection: S.G. and K.Y.; Analysis: S.G. and K.Y.; Literature Search: S.G. and K.Y.; Writing Manuscript: S.G. and K.Y.; Critical Review: S.G., K.Y., S.G. and M.G.W.

Conflict of Interest: The authors have no conflicts of interest to declare.

Financial Disclosure: The authors declared that this study has received no financial support

Cite this paper as: Gülci, S., Yüksel, K., Gumus, S., Wing, M.G., 2021. Mapping Wildfires Using Sentinel 2 MSI and Landsat 8 Imagery: Spatial Data Generation for Forestry, European Journal of Forest Engineering, 7(2):57-66.

\section{References}

Akay, A. E., Şahin, H., 2019. Forest fire risk mapping by using GIS techniques and AHP Method: A case study in Bodrum (Turkey). Eur. J. For. Res., 5(1): 25-35.

Arıcak, B., Enez, K., Küçük, Ö., 2012. Determining Fire Potential by Using Satellite Images, KSU J. Engineering Sci., Special Issue: 220-225.

Ateşoğlu, A., 2014. Forest fire hazard identifying. mapping using satellite imagery-geographic information system and analytic hierarchy process: Bartın, Turkey. J. Environ. Prot. Ecol., 15(2): 715725

Atun, R., Kalkan, K., Gürsoy, Ö., 2020. Determining the forest fire risk with Sentinel 2 images. Turkish Journal of Geosciences, 1(1): 22-26. 
Barrow, C. J., 1993. Caring for the earth: A strategy for sustainable living, published by IUCN (World Conservation Union), UNEP (United Nations Environment Programme) and WWF (World Wide Fund for Nature). J. Int. Dev., 5(3): 352-352.

Bolton, D. K.,Coops, N. C., Wulder, M. A., 2015. Characterizing residual structure and forest recovery following high-severity fire in the western boreal of Canada using landsat time series and airborne LiDAR data. Remote Sens. of Environ., 163: 48-60.

Cavdaroglu, G.C., 2021. Google Earth Engine based approach for finding fire locations and burned areas in Muğla, Turkey. American Journal of Remote Sensing, 9(2), 72-77.

Çepel, N., 2002. Ekolojik Sorunlar ve Çözümleri. TÜBİTAK Bilim Kitapları, 180, 3. Basım, 2003. Ankara, s. 183. (In Turkish)

Chuvieco, E. (Ed.)., 2009. Earth observation of wildland fires in Mediterranean ecosystems Dordrecht, the Netherlands: Springer. pp. 129-148.

Çoban, H., Özdamar, S., 2014. Mapping forest fire in relation to land-cover and topographic characteristics. J. Environ. Biol., 35(1): 217-224.

Cocke, A. E., Fulé, P. Z., Crouse, J. E., 2005. Comparison of burn severity assessments using differenced Normalized Burn Ratio and ground data. Int. J. Wildland Fire, 14(2): 189-198.

Congalton, R. G., 2001. Accuracy assessment and validation of remotely sensed and other spatial information. Int. J. Wildland Fire, 10(4): 321-328.

Erdas., 1997. ERDAS Field Guide. Atlanta.

Erten, E., Kurgun, V., Musaoglu, N., 2004. Forest fire risk zone mapping from satellite imagery and GIS: a case study. In $\mathrm{XX}^{\text {th }}$ Congress of the International Society for Photogrammetry and Remote Sensing, Istanbul, Turkey (pp. 222-230).

ESA., 2021. Specification of Sentinel 2 MSI. Online: https://sentinels.copernicus.eu/web/sentinel/userguides/sentinel-2-msi/overview 10.10.2021)

Esri., 1996. Using ArcView GIS: user manual. Redlands: Environmental Systems Research Institute.

FAO., 2021. "Sustainable forest management" Online: https://www.fao.org/forestry/sfm/en/. (Accessed: 18.09.2021)

Fuller, D., 2000. Satellite remote sensing of biomass burning with optical and thermal sensors. Progress in Physical Geography, 24(4): 543-561.

Gorelick, N., Hancher, M., Dixon, M., Ilyushchenko, S., Thau, D., Moore, R., 2017. Google Earth Engine: Planetary-scale geospatial analysis for everyone. Remote Sens. Environ. 202: 18-27.

Gülci, N., 2021. Estimating costs of salvage logging for large-scale burned forestlands: A case study on Turkey's Mediterranean coast. J. For. Res. 32(5): 1899-1909.

Gulci, S., Akay, A. E., Yuksel, K., 2016. Evaluating capabilities of using thermal imagery for detecting impacts of forest operations on residual forests. In Living Planet Symposium,2016, August. 740, p. 193.

Gülci, S., Gülci, N., Yüksel, K., 2019. Monitoring Water Surface Area and Land Cover Change by using Landsat Imagery for Aslantaş Dam Lake and Its Vicinity. Journal of the Institute of Science and Technology, 9(1): 100-110.

Keeley, J.E., 2009. Fire intensity, fire severity and burn severity: A brief review and suggested usage. Int. J. Wildland Fire, 18(1): 116-126.

Key, C.H., Benson, N.C., 2006. Landscape assessment: Remote sensing of severity, the Normalized Burn Ratio. In FIREMON: Fire Effects Monitoring and Inventory System; USDA Forest Service, Rocky Mountain Research Station, Fort Collins: Denver, CO, USA, pp. 305-325.

Konkathi, P., Shetty, A., 2021. Inter comparison of postfire burn severity indices of Landsat- 8 and Sentinel-2 imagery using Google Earth Engine. Earth Sci Inform 14, 645-653.

Küçük, Ö., Bilgili, E., 2006. The conveyance of fire behavior characteristics into practice by using Geographical Information Sysyems (GIS): A Case Study in Kastamonu, Kastamonu University Journal of Forestry Faculty 6(2): 262-273.

Miller, J. D., Thode, A. E., 2007. Quantifying burn severity in a heterogeneous landscape with a relative version of the delta Normalized Burn Ratio (dNBR). Remote Sens. of Environ. 109(1): 66-80.

Nasi, R., Dennis, R., Meijaard, E., Applegate, G., Moore, P., 2002. Forest fire and biological diversity. UNASYLVA-FAO, 36-40.

Nemani, R., Votava, P., Michaelis, A., Melton, F., Milesi, C., 2011. Collaborative super computing for global change science EOS Trans. Am. Geophys. Union. 92(13): 109-110.

Pan, X., Wang, Z., Gao, Y., Dang, X., \& Han, Y. (2021). Detailed and automated classification of land use/land cover using machine learning algorithms in Google Earth Engine. Geocarto Int. 1-18.

Picotte, J. J., Cansler, C. A., Kolden, C. A., Lutz, J. A., Key, C., Benson, N. C., Robertson, K. M., 2021. Determination of burn severity models ranging from regional to national scales for the conterminous United States. Remote Sens. Environ. 263: 112569.

Quintano, C., Fernández-Manso, A., Fernández-Manso, O., 2018. Combination of Landsat and Sentinel-2 MSI data for initial assessing of burn severity. Appl Earth Obs Geoinf. 64: 221-225.

Sabuncu, A., Özener, H., 2019. Detection of Burned Areas by Remote Sensing Techniques: İzmir Seferihisar Forest fire case study. Journal of Natural Hazards and Environment, 5(2), 317-326.

Stephens, S. L., Collins, B. M., Fettig, C. J., Finney, M. A., Hoffman, C. M., Knapp, E. E., North, M. P., Safford, H., Wayman, R. B., 2018. Drought, tree mortality, and wildfire in forests adapted to frequent fire. BioScience, 68(2): 77-88. 
UNOOSA (The United Nations Office for Outer Space Affairs)., 2018. Step by Step: Burn Severity mapping in Google Earth Engine, Submitted by Johannes Heisig on Tue, 04/12/2018 - 13:54. Online: http://www.un-spider.org/advisorysupport/recommended-practices/recommendedpractice-burn-severity/burn-severity-earth-engine. (Accessed: 10.08.2021)

USDA (United States Department of Agriculture)., 2006. FIREMON: Fire Effects Monitoring and Inventory System. USDA Forest Service Gen. Tech. Rep. RMRS-GTR-164-CD. https://www.fs.fed.us/rm/pubs/ rmrs_gtr164.pdf FIREMON BR CheatSheet V4, June 2004.

USGS., 2021. The bands specification of Landsat 8 . Online: https://www.usgs.gov/media/images/landsat8-band-designations (Accessed: 10.10.2021)

Wing, M. G., Burnett, J. D., Sessions, J., 2014. Remote sensing and unmanned aerial system technology for monitoring and quantifying forest fire impacts. Int. J. Remote Sens. Appl. 4(1): 18-35.

Wulder, M. A., Hall, R. J., Franklin, S. E., 2005. Remote sensing and GIS in forestry. Remote sensing for GIS managers. ESRI Press, Redlands, 351-362. 